\title{
Determination of Shear Strength Parameters by Multistage Triaxial Tests in the Long-Term Analysis of Slopes
}

\author{
Dua Kayaturk ${ }^{*}$ (D), Ertan Bol$^{2}$ (D), Sedat Sert ${ }^{2}$ iD), Askin Ozocak² \\ ${ }^{1}$ Department of Civil Engineering, Sakarya University of Applied Sciences, Turkey \\ ${ }^{2}$ Department of Civil Engineering, Sakarya University, Turkey
}

Received: / Accepted: 04-June-2021 / 27-June-2021

\begin{abstract}
Accurate determination of soil parameters is of great importance in the analysis of landslides, which is a common type of natural disaster. In the solution of landslide problems, the direct shear box test is generally preferred as a laboratory test type for the determination of the shear strength parameters of soils. However, the need for drained parameters in long-term problems reveals a disadvantageous aspect of this experiment, especially in clayey soils, because pore water pressures cannot be measured in the direct shear box test, which is widely used in the laboratory to determine the shear strength of the soils.

Multistage triaxial compression tests used to obtain shear strength parameters in the laboratory are advantageous compared to conventional triaxial compression tests because of the time and financial concerns, as well as the avoidance of differences between the samples to be tested. In this study, a new method was tried in addition to the methods used to obtain shear strength parameters with consolidated-drained multistage tests in normally consolidated clayey soils and the results were promising. Thus, since it increases the usability of multistage tests, it will be helpful in terms of preventing possible disasters by enabling analysis in many more sites.
\end{abstract}

Key words: Landslides, multistage triaxial test, long-term analysis

\section{Introduction}

In the analysis of landslides, it is crucial to correctly determine the soil's cohesion and internal friction angle. Stability problems of natural slopes are determined by effective parameters in the long-term analysis. To assess these effective parameters in the laboratory, it is necessary to measure the pore water pressures, which change with increasing axial stresses. Direct shearing tests and triaxial tests are widely used in the laboratory to measure effective shear strength parameters. Since pore water pressure measurements cannot be made during conventional direct shear box tests, it is impossible to control whether the test is drained or not, especially on clayey soils. Although there are methods to determine the shearing rate for drained shearing in the literature, the fact that there is no direct observation of a change in pore water pressure makes the test questionable. Therefore, it is preferable to perform the drained tests on clayey soils with a triaxial test.

Consolidated-undrained (CU) or consolidated-drained (CD) test type is preferred to find the effective shear strength parameters in the triaxial test. CD tests, which are also used in the analysis of slope stability, are the tests in which the effective shear strength parameters are

\footnotetext{
* Corresponding Author e-mail: dua@subu.edu.tr
} 
obtained and must be conducted very slowly to prevent excess pore water pressures in the sample in low permeability soils. The effective shear strength is determined by the tests performed on the core samples taken from the field to define the soil properties where the stability analysis will be performed. Sometimes, it is necessary to work with several samples in the same layer at the same depth, and at least three tests should be carried out on the specific soil to determine the shear strength. There will likely be differences between core samples taken from the field in this standard practice, and standard CD tests take a lot of time to run. Besides, economic concerns cannot be ignored.

The multistage $\mathrm{CD}$ tests on a sample representative of the soil property can be used to save time and reduce costs in applications where embankment dams, excavations in soft and solid clays or the stability of slopes are the most critical conditions. Within the scope of this study, multistage CD tests, which are considered practical compared to conventional methods, were used in the rapid and economic analysis of natural disasters, such as landslides, where slope stability should be examined. Conventional triaxial tests and multistage testing were performed on normal consolidated clayey silt samples. In order to obtain the effective shear strength parameters of the samples, a new method has been proposed and evaluated besides the method used in the literature. Kondner's [1] hyperbolic relationships were used to estimate the deviator stress at failure from stress-strain data obtained from multistage tests [2]. Nambiar [3] mentioned that an additional conventional test should be performed in order to obtain shear strength parameters from multistage tests. Within the scope of this study, obtaining shear strength parameters from multistage tests with a new method without the need for an additional conventional test was investigated.

\section{Testing Program and Results}

The soil used in this study was classified as a clayey soil (CL) according to the TS-1500 [4]. The soil is consists of $27 \%$ clay, $\% 73$ silt. It has specific gravity of 2.66 , liquid limit of $30.3 \%$, plastic limit of $22.85 \%$, maximum dry unit weight of $15.18 \mathrm{kN} / \mathrm{m}^{3}$ and optimum moisture content of $25.63 \%$. Prior to the multistage test, conventional consolidated drained (CD) tests were performed on the samples to determine the cohesion and angle of internal friction. In this way, it was aimed to compare the shear strength parameters obtained from conventional tests with those obtained from the multistage test.

The consolidated drained (CD) tests were performed on reconstituted cylindrical samples. Reconstituted cylindrical samples were prepared with the uniaxial consolidation of soil slurries method. Samples were reconstituted at $100 \mathrm{kPa}$ consolidation pressure. According to ASTM D7181 [5], a sample dimensions ratio (height to diameter) between 2 and 2.5 is recommended. Therefore, reconstituted samples had dimensions of diameter $50 \mathrm{~mm}$ and height of $100 \mathrm{~mm}$. In both conventional and multistage tests, the preparation of the sample and its placement in the triaxial test apparatus was performed identically.

The lines were saturated by flushing water through de-airing and checking of the connecting lines and the drainage system. The reconstituted sample with top, bottom, and side filters was placed on a base pedestal with top and bottom saturated porous disks. Afterward, placing the specimen in position, a standard rubber membrane was used to contain the samples laterally, and two pairs of O-rings were used to fit the rubber membrane with each of the base pedestal and the top cap to ensure the separation of the cell and back pressures applied to the samples. By assembling the test equipment and filling the test cell with water, the sample was ready for the triaxial test. 
Each conventional triaxial test consisted of three phases: saturation, consolidation, and shearing. During the saturation phase of the test, the sample was subjected to incremental confining or cell pressure steps $\sigma_{\mathrm{c}}=\sigma_{3}$ between 50 and $500 \mathrm{kPa}$, along with back pressure differential was $10 \mathrm{kPa}$, that is, incremental back pressure steps 40 and $490 \mathrm{kPa}$. With the B value calculated in each step of the saturation phase, it was followed whether the sample was at $95 \%$ saturation. The objective of the saturation phase of the test is to replace the voids in the sample with water and prevent the formation of different undesirable stresses in the sample, and this process can take days from time to time in unsaturated samples. In this study, the saturation phase lasted between 2 and 3 hours because the reconstituted samples were saturated. The saturation phase was applied the same in both conventional and multistage test.

In the consolidation phase, the sample was consolidated by creating the same stresses in whatever effective stress the specimen will be shear in the shearing phase. During consolidation, the sample reached equilibrium in a drained state, and the strain rate to be used in the shearing stage was determined with the data obtained at the consolidation stage. During the consolidation phase of conventional triaxial tests, data is obtained for use in determining when consolidation is complete and computing a strain rate to be used for the shear portion of the test. The strain rate was determined by following the ASTM D7181 [5] standard with the t9o parameters obtained from the square root time and deformation graphs. When the strain rates used in the literature are examined, Ho and Fredlund [6] used the consolidation coefficient for the selection of the strain rate in their multistage tests on unsaturated soils and the strain rate was $0.001 \mathrm{~mm} / \mathrm{min}$; Banerjee et al. [7] conducted multistage consolidated-drained tests on unsaturated clayey soil and the strain rate was $0.003 \% / \mathrm{min}$; Hormdee et al. [8] used $0.002 \% / \mathrm{min}$ as the strain rate in their multistage tests on silty clayey soils. Sharma et al. [9] determined the strain rate as $0.005 \% / \mathrm{min}$ in order to have enough time to end each loading stage and then move on to the next stage in multistage consolidated-drained tests conducted on silty sands. Also, in general laboratory tests, Skempton [10] suggested a shearing rate of $0.005 \mathrm{~mm} / \mathrm{min}$. Considering the data obtained from the consolidation phase and literature studies, the strain rate was determined as $0.005 \mathrm{~mm} / \mathrm{min}$.

In the shearing phase that started after the consolidation phase, the samples were subjected to confining pressures of $100,200,300 \mathrm{kPa}$ to determine the Mohr strength envelopes. The samples were sheared until $20 \%$ deformation occurred in the samples.

The stress-strain curves of conventional triaxial tests (CTTs) to check the accuracy of the data in multistage test are shown in Figure 1. The effective shear strength parameters according to the failure envelope created by using peak deviator stresses in stress-strain curves obtained from conventional tests are as follows: $\mathrm{c}^{\prime}=20.98, \phi^{\prime}=33.17$.

Ho and Fredlund [6] mentioned two methods in multistage shear tests. One is the cyclic loading method, in which the load on the sample is removed after the shearing is terminated and the next consolidation stage is passed, and the other is the sustained loading method, in which the load is maintained in the consolidation phase after the shearing is terminated. In the sustained loading method, keeping the load on the sample between stages might continue to deform the sample. For this reason, cyclic loading method was preferred in this study for multistage triaxial test. Figure 2 shows the stress-strain curve obtained from cyclic multistage test (MST).

In multistage test, the sample was subjected to all of the effective stresses applied in conventional tests to determine the Mohr strength envelope in increasing order. After the multistage test specimen was saturated as in the conventional test, it was consolidated at 
effective stress of $100 \mathrm{kPa}$ and then sheared at the same effective stress. The sample was sheared to a certain deformation was consolidated by subjecting it to effective stress of $200 \mathrm{kPa}$ for the second consolidation. After the second consolidation, the sample was sheared to a certain deformation with effective stress of $200 \mathrm{kPa}$ and subjected to effective stress of $300 \mathrm{kPa}$ for the third consolidation. The effective stresses at each consolidation stage were the same as the effective stress value in the shearing stage following the consolidation stage. In each shearing stage of the multistage test, a shearing rate of $0.005 \mathrm{~mm} / \mathrm{min}$ was used as in the conventional tests. In this study, the multistage test was carried out by shear the sample until it reached a deformation of $4.5 \%$ in the first two stages and in the third stage, which was the last stage, until the sample reached $20 \%$ deformation. The stress-strain curves of the multistage test (MST) are shown in Figure 3.

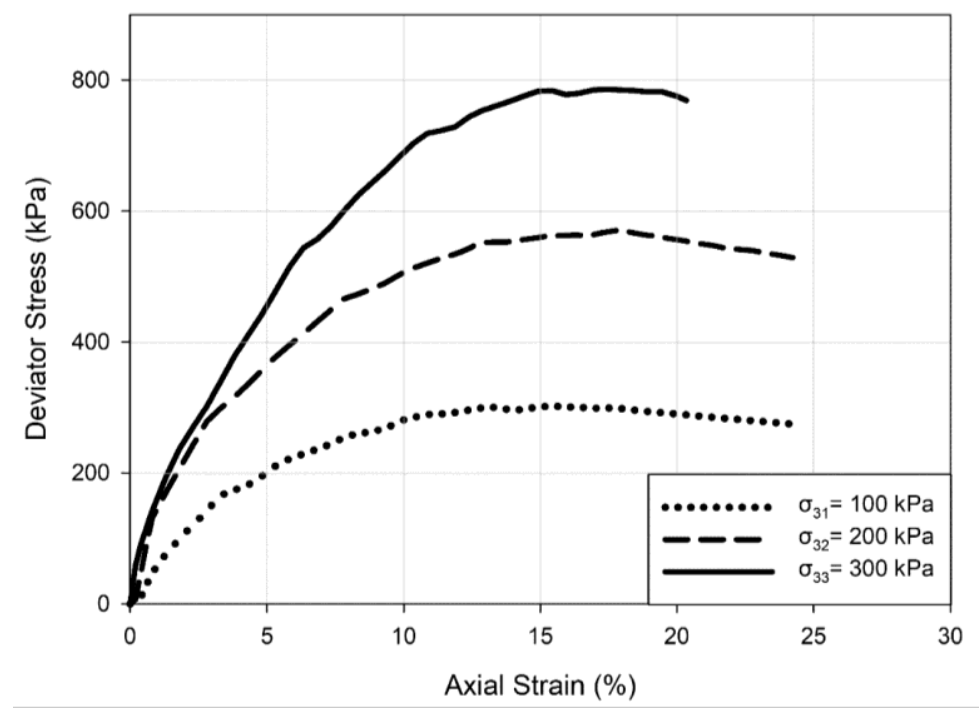

Figure 1. Stress-strain curves of the CTTs

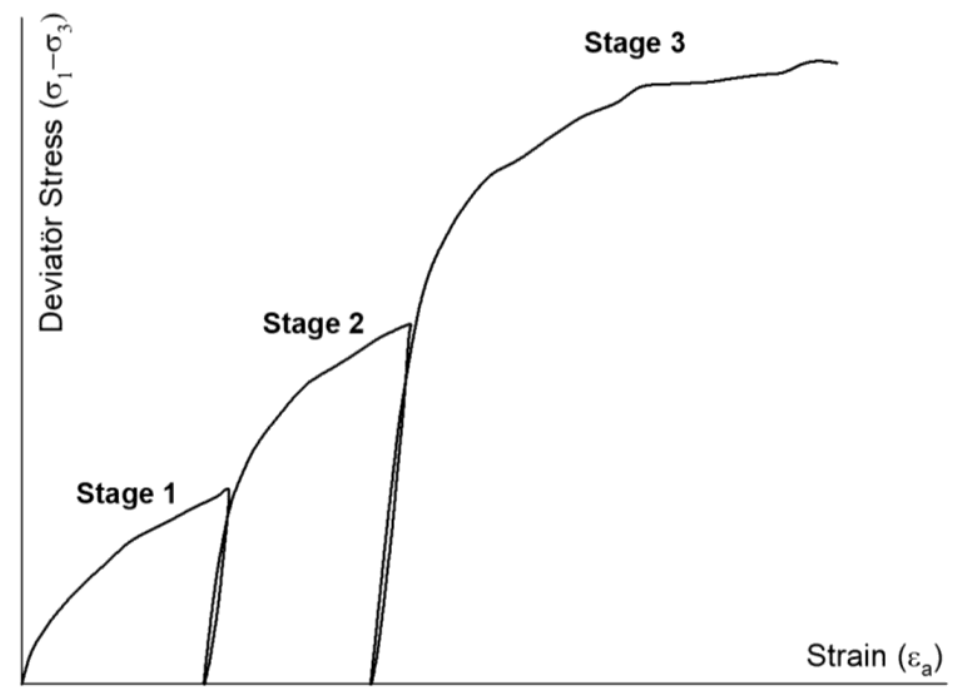

Figure 2. Stress-strain curve of the cyclic MST 


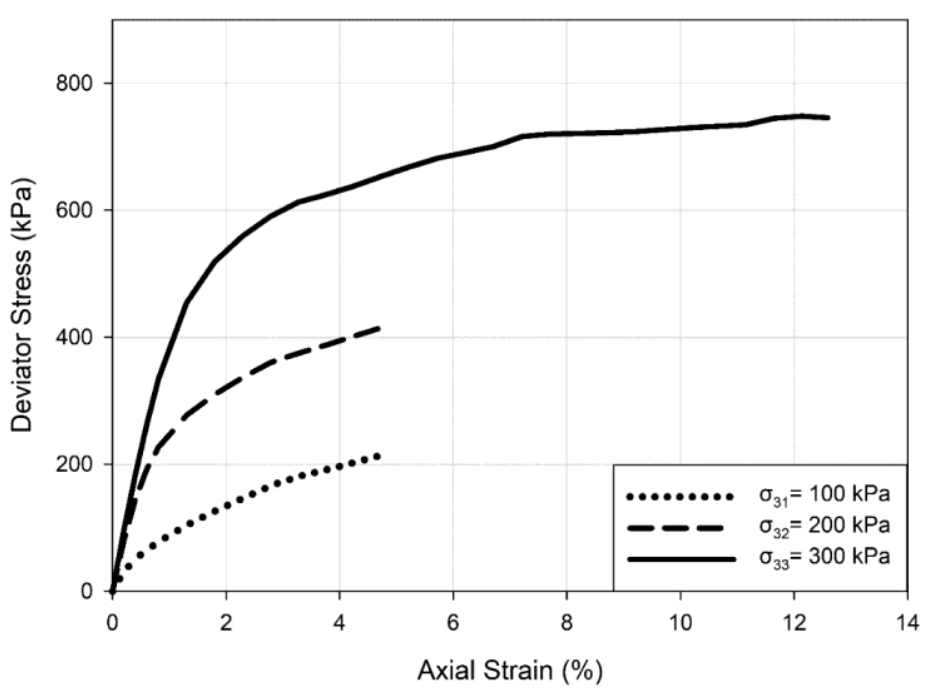

Figure 3. Stress-strain curves of the MST

Kondner's [1] hyperbolic relationships were used to estimate the deviator stress at failure from stress-strain data obtained from multistage tests [2]. Kondner's method mathematically expressed as:

$$
\frac{\varepsilon_{a}}{\sigma_{1}-\sigma_{3}}=a+b \varepsilon_{a}
$$

where; $\varepsilon_{a}$ is the axial strain, $\sigma_{1}-\sigma_{3}$ is the deviator stress, $a$ and $b$ are empirical constants that can be obtained experimentally from Kondner's linearization. A plot of $\varepsilon_{a} /\left(\sigma_{1}-\sigma_{3}\right)$ vs. $\varepsilon_{a}$ is a straight line in which its slope gives the value of $\mathrm{b}$, and its intercept with the axis of $\varepsilon_{a} /\left(\sigma_{1}-\right.$ $\sigma_{3}$ ) gives the value of a [11].

The hyperbolic linearization of the data obtained from the multistage test using Eq. 1 is depicted in Figure 4. The stresses at $20 \%$ deformation of the lines formed using this linearization were accepted as the deviator stress. The effective shear strength parameters obtained by forming the failure envelope with these deviator stresses are as follows: $c^{\prime}=12.39, \phi^{\prime}=32.59$.

In this study, estimated stress-strain curves were created with the data obtained from the multistage test using Eq.2 the 2-parameter logarithmic equation with the curve fitting method in statistical software.

$$
y=y_{0}+\operatorname{aln} x
$$

where; $x$ is the axial strain; $y$ : is the deviator stress, $y_{0}$ and $a$ are constants obtained for Eq. 1 by introducing the multistage test data into the statistical software.

The estimated stress-strain curves with the curve fitting method are shown in Figure 5. Accordingly, the estimated deformation curves obtained from the first and second stages seem to be quite compatible with the curves obtained from conventional tests, but the same compatible is not available for the final stage. The axial deformations in the first and second stages were kept within the range of $2-4 \%$ in order to prevent plastic deformations from occurring in the sample during multistage tests, and the estimated deviator stresses to be obtained from Kondner and curve fitting methods were insufficient due to the low stress-strain data obtained [12]. 


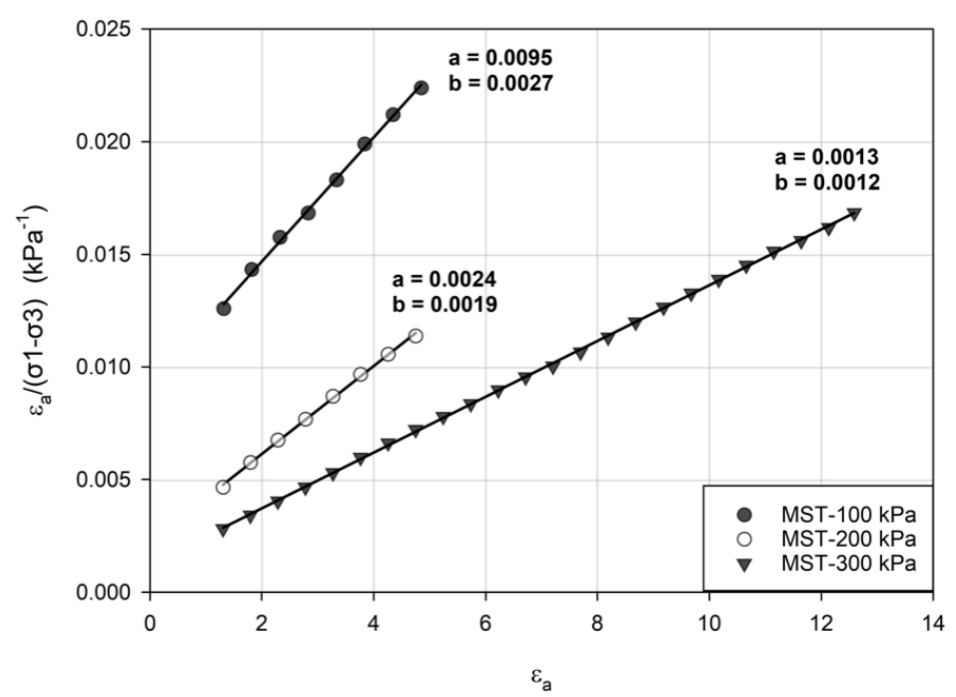

Figure 4. Hyperbolic linearization of the MST

It is thought that the estimated stress for $20 \%$ deformation with the curve fitting method at the final stage is greater than the stress obtained from conventional tests using $300 \mathrm{kPa}$ confining pressure, which would be misleading for the estimation of shear strength parameters. The results obtained with the curve fitting method for all three stages are as follows: $c^{\prime}=2.16$, $\phi^{\prime}=35.81$. In the Pagoulatos study [13], it was mentioned that the peak deviator stress could be taken from the last stage, since failure occurs in the last stage of the multistage test. The effective shear strength parameters obtained by using the peak deviator stress obtained from the last stage of the multistage test and the $20 \%$ deformation stresses of the curves formed by the curve fitting method to create the failure envelope are as follows: $c^{\prime}=29.5, \phi^{\prime}=31.84$. The closeness of the shear strength parameters obtained by the curve fitting \& MST peak deviator method with those obtained from conventional tests indicates that this method can be used.

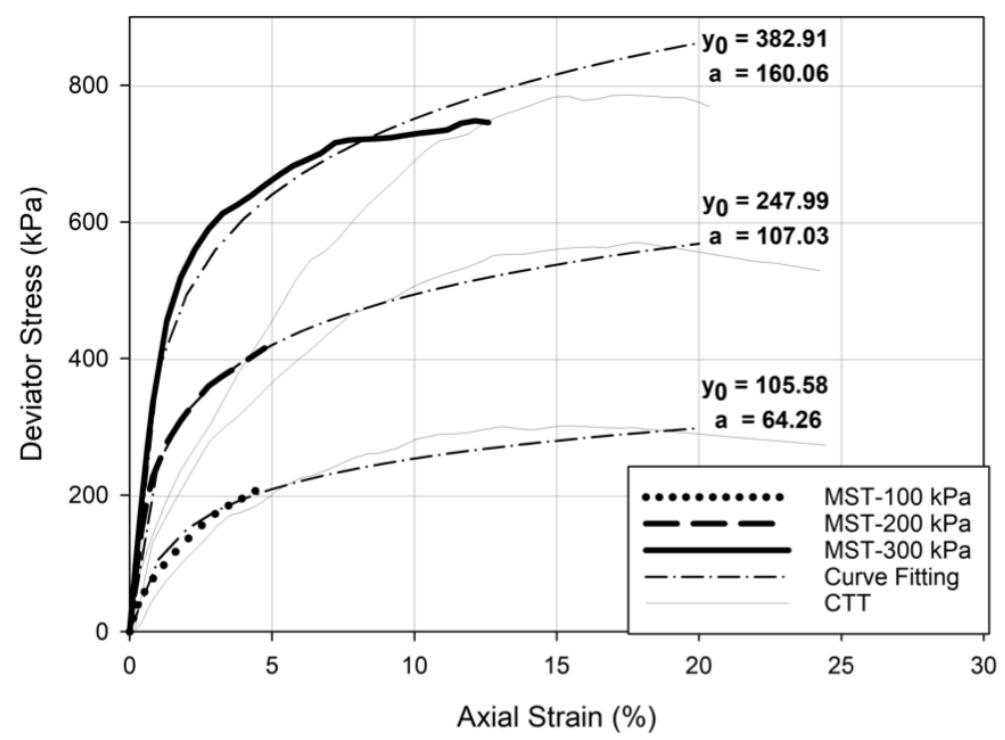

Figure 5. Stress-strain curves of the MST test with curve fitting method

When the shear strength parameters obtained by both the Kondner method and the curve fitting $\&$ MST peak deviator methods are examined, it is seen that the angle of failure values are very close to each other. However, it is difficult to mention the same agreement for cohesion strength. The cohesive strength obtained from the first method was lower than that obtained 
from the conventional tests, and the cohesive strength obtained from the second method was higher than that obtained from the conventional tests. The averages of the cohesion values obtained from the two different methods used in this study were found to be close to the results obtained from the conventional tests. The shear strength parameters obtained by using different methods within the scope of this study are summarized in Table 1.

Table 1. Shear strength parameters obtained from the methods

\begin{tabular}{|c|c|c|c|c|c|}
\hline & $\begin{array}{c}\text { (1) } \\
\text { CTT }\end{array}$ & $\begin{array}{c}\text { (2) } \\
\text { MST } \\
\text { Kondner }\end{array}$ & $\begin{array}{c}\text { (3) } \\
\text { MST } \\
\text { Curve Fitting }\end{array}$ & $\begin{array}{c}\text { (4) } \\
\text { MST } \\
\text { Curve Fitting } \\
\text { \& MST Peak } \\
\text { Deviator St. }\end{array}$ & $\begin{array}{c}(5) \\
\text { Average } \\
\text { Values } \\
(2: 4)\end{array}$ \\
\hline $\mathbf{c}^{\prime}$ & 20.98 & 12.39 & 2.16 & 29.5 & 20.95 \\
\hline$\phi^{\prime}$ & 33.17 & 32.59 & 35.81 & 31.84 & 32.22 \\
\hline
\end{tabular}

\section{Conclusions}

It is essential to determine soil parameters in the analysis of landslides, which is one of the frequently encountered natural disaster types. The last a long time of the experimental processes and the need for multiple samples have strengthened the concept of multistage in obtaining the drained shear strength parameters needed for long-term analyses. Preventing variations in samples and minimizing financial and temporal concerns make multistage tests advantageous compared to conventional tests. This can make the analyzes of landslides more practical and make much more analysis, thus minimizing loss of life and property. Of course, at this point, the accuracy of the results obtained from multistage tests is crucial.

In this study, consolidated drained multistage test and conventional triaxial tests were carried out on normally consolidated clayey soils. A new method has been proposed by using the method applied in the literature to obtain shear strength parameters from the multistage test without the need for another conventional test. The new method resulted in $0 \%$ and 3\% difference for the estimated shear strength parameters $c^{\prime}$ and $\phi^{\prime}$ obtained from the multistage test, respectively, when compared with parameters obtained from conventional tests. Although this new method was tested for a single soil type, the results were promising. This developed method can be tested on different soils and the study can be improved.

\section{Author Contribution}

Kayaturk and Bol designed the model and the experimental framework. Kayaturk conducted the experimental process and performed the calculations. Kayaturk, Bol and Sert wrote the manuscript with input from all authors. Kayaturk, Bol and Sert and Ozocak contributed to the analysis of the results. 


\section{References}

[1] Kondner R.L., Hyperbolic stress-strain response: cohesive soils: Journal of Soil Mechanics and Foundations Division Vol. 89 (1963), p. 115-143.

[2] Sridharan, A. M., and S. N. Rao. 1972. New approach to multistage triaxial test. Journal of Soil Mechanics and Foundations Division 98: 1279-1286.

[3] Nambiar M.R., G.V. Rao and S.K. Gulhati, Multistage triaxial testing: A rational procedure: Strength Testing of Marine Sediments: Laboratory and In-Situ Measurements Vol. 883 (1985), p. 274-293.

[4] TS 1500, İnşaat Mühendisliğinde Zeminlerin Sınıflandırılması, Türk Standartları Enstitüsü, Ankara, 2000.

[5] ASTM. 2015. Annual Book of ASTM Standards. Vol. 04.08 \& 04.09. West Conshohocken, PA: American Society for Testing and Materials.

[6] Ho, D. Y. F., and D. G. Fredlund. 1982. A Multistage Triaxial Test for Unsaturated Soils. Geotechnical Testing Journal (Americal Society for Testing and Materials) 5 (1/2): 1825.

[7] Banerjee, A., Puppala, A. J., \& Hoyos, L. R. 2020. Suction-controlled multistage triaxial testing on clayey silty soil. Engineering Geology, 265, 105409.

[8] Hormdee D., Kaikeerati N. and Angsuwotai, P. 2012. Evaluation on the Results of Multistage Shear Test Int Jl GEOMATE, 2 (1), 140-143.

[9] Sharma, M. S., Baxter, C. D., Moran, K., Vaziri, H., \& Narayanasamy, R. (2011). Strength of weakly cemented sands from drained multistage triaxial tests. Journal of geotechnical and geoenvironmental engineering. 137(12), 1202-1210.

[10] Skempton, A. W., 1985. Residual Strength of Clays in Landslides, Folded Strata and the Laboratory, Geotechnique, Vol.35, No.1, 3-18.

[11] Shahin M., Cargeeg A. 2011. Experimental Investigation into Multistage versus Conventional Triaxial Compression Tests for a c-phi Soil. Applied Mechanics and Materials. Vol. 90-93.

[12] Kayatürk D., 2021. Multistage Testing on clayey soils. M.S. thesis, in progress. Sakarya University, Sakarya, Turkey

[13] Pagoulatos, A. 2004. Evaluation of multistage triaxial testing on Berea sandstone. M.S. thesis, Univ. of Oklahoma, Norman, OK. 